\title{
Effect of micronization on Physicochemical Properties of Tapioca Starch
}

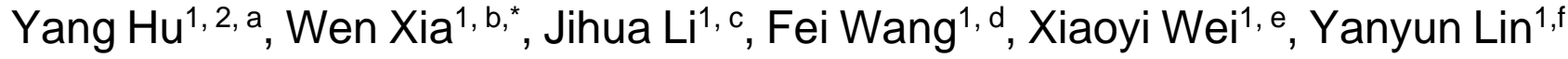 \\ ${ }^{1}$ Key Laboratory of Tropical Crop Products Processing of Ministry of Agriculture, Agricultural \\ Products Processing Research Institute, Chinese Academy of Tropical Agricultural Sciences, \\ Zhanjiang, 524001, China \\ ${ }^{2}$ College of Food Science and Technology of Huazhong Agricultural University, No. 1, Shizishan \\ Road, Hongshan District, Wuhan, Hubei Province, 430070,China \\ a401461951@qq.com, bxiawensg@163.com, cfoodpaper@126.com, d185541703@qq.com, \\ eweixywei@163.com, f604102100@qq.com
}

Keywords: Micronization; Tapioca starch; solubility; swelling; enzymolysis.

\begin{abstract}
The purpose of this study was to investigate the physicochemical properties of tapioca starch (TS) after micronization.The thermal properties analysis suggested that the gelatinization temperature was decreased after the treatment of micronization and decreased with increasing processing time. Solubility and swelling properties analysis showed that the solubility of TS was dramatically increased from $0.93 \%, 1.94 \%, 3.59 \%, 20.90 \%, 24.71 \%$ to $81.63 \%, 87.15 \%, 92.67 \%$, $94.19 \%, 95.50 \%$ after micronization at $50^{\circ} \mathrm{C}, 60^{\circ} \mathrm{C}, 70^{\circ} \mathrm{C}, 80^{\circ} \mathrm{C}$ and $90^{\circ} \mathrm{C}$ respectively, while the swelling was decreased. Enzymolysis analysis demonstrated that the enzymatic hydrolysis rate was significantly increased after micronization from $0.0012 \mathrm{~g} / \mathrm{min}$ to $0.1493 \mathrm{~g} / \mathrm{min}$. These results provided the basic information on the physicochemical properties of tapioca starch after micronization..
\end{abstract}

\section{Introduction}

Tapioca starch (TS) is widely produced in Latin America and is also one of the most important industrial crops in Thailand. It shows lower pasting temperature, higher viscosity[1], higher amylopectin content and relatively lower price when compared to other starch in the world market [2], which makes it suitable for food industries.

Micronization is an important technique which was widely used in food processing to make ultra-fine powder. The ultra-fine powder has many particular characteristics, such as increasing the utilization rate of materials, improving the processing performances and the quality of products. Wu et al. (2008) studied that enzymatic hydrolysis rate of corn starch improved sharply after micronization[3].Fu et al. (2015) Suggested the solubility and enzymatic hydrolysis rate of waxy rice starch increased remarkably after high speed jet[4]. However, only a few reports study the effect of micronization on physicochemical properties of tapioca starch. The objective of this research was to study the tapioca starch prepared by micronization, and its physicochemical properties were also investigated.

\section{Experimental}

\subsection{Materials.}

The purity degree of tapioca starch (Thai World Import and Export, Bangkok, Thailand) was $99.7 \%$ (dry weight basis) and it was purchased from a food factory in Thailand. All chemicals used were of analytical grade.

\subsection{Preparation of Samples After Micronization}

Micronized starch prepared by a vibrating superfine mill (WZJ6, China ) with a micronization time of $10 \mathrm{~min}, 20 \mathrm{~min}, 30 \mathrm{~min}, 40 \mathrm{~min}, 50 \mathrm{~min}$ and $60 \mathrm{~min}$. 


\subsection{Determination of Thermodynamic Properties.}

Samples $(3 \mathrm{mg}, \mathrm{db})$ were placed in a aluminum DSC pan and a certain amount of sodium azide distilled water $(0.02 \%, \mathrm{w} / \mathrm{w})$ was added by a microsyringe to obtain a ratio of $1: 2.5(\mathrm{w} / \mathrm{v})$. The sample pan was sealed,then equilibrated at room temperature for $5 \mathrm{~h}$, and then heated from $10^{\circ} \mathrm{C}$ to $100^{\circ} \mathrm{C}$ at a heating rate of $10^{\circ} \mathrm{C} / \mathrm{min}$. The onset temperature $\left(\mathrm{T}_{0}\right)$,peak temperature $\left(\mathrm{T}_{\mathrm{p}}\right)$, conclusion temperature $\left(\mathrm{T}_{\mathfrak{c}}\right)$ and gelatinization enthalpy $\left(\triangle \mathrm{H}_{\mathrm{g}}\right)$ were recorded[5].

\subsection{Determination of Solubility Properties and Swelling Properties}

.Strach samples $(1 \mathrm{~g}$,different treatment times) were suspended in water with sitrring for $30 \mathrm{~min}$ at $50^{\circ} \mathrm{C}, 60^{\circ} \mathrm{C}, 70^{\circ} \mathrm{C}, 80^{\circ} \mathrm{C}$ and $90^{\circ} \mathrm{C}$ respectively, centrifuged at $4000 \mathrm{rpm}$ for $15 \mathrm{~min}$. The supernatant was solubilized starch, part of the paste subsidence was expansion of starch. To separate the supernatant and precipitated paste,evaporated to dryness in a water bath $105^{\circ} \mathrm{C}$ to constant weight. that is, the amount of solubilized starch and the amount of expanded starch,calculated the solubility and swelling degree.

$$
\begin{aligned}
& \text { Solubility }=\frac{\text { soluble starch weight }(\mathrm{g})}{\text { starch sample weight }(\mathrm{g})} \times 100 \% \\
& \text { Swelling degree }=\frac{\text { expanded starch weigh }(\mathrm{g})}{[\text { starch sample weight }(\mathrm{g}) \times(100 \text { - solubility })]} \times 100 \%
\end{aligned}
$$

\subsection{Determination of Enzymatic Resolution}

Starch samples(3.00 g)of different treatment time was weighed respectively ; then water was added to volume to $50 \mathrm{~mL}$. The samples were heated at $100^{\circ} \mathrm{C}$ for $15 \mathrm{~min}$ to be completely gelatinized. When the samples were cooled to $58^{\circ} \mathrm{C}, 1 \mathrm{~mL}$ of $\alpha$-amylase was added and hydrolyzed for $15 \mathrm{~min}$, and then keeping stirring. The filtrate obtained was filtered through a filter paper which has been weighed and washed with alcohol and diethyl ether. The mixture was dried at $105^{\circ} \mathrm{C}$ until constant weight, and the weight of the residue was recorded. The Enzyme hydrolysis rate was calculated using the following equation:

$$
\text { Enzymolysis rate }(\mathrm{g} / \mathrm{min})=\frac{\text { the weight of residue }(\mathrm{g})}{\text { time }(\min )}
$$

\section{Results and Discussion}

\subsection{Thermal Properties of Micronized Tapioca Starch.}

The DSC thermogram of samples is shown in Fig.1.It demonstrated that the endothermic peak was gradually flat and TS was more easily to gelatinization with the increasing of micronization time, which indicated gelatinization transition temperatures and the enthalpy of gelatinization $\left(\triangle \mathrm{Hg}_{\mathrm{g}}\right)$ shifted to lower values with increasing the time of micronization. The reason was hat the sharp mechanical shear destroyed the starch molecule with the increase of micronization time, which led to the acceleration of the debranching rate of branch structure and the disintegration rate of ordered structure. An increasing number of amorphous starch molecules were formed and the gelatinization of starch will happen more eaily. 


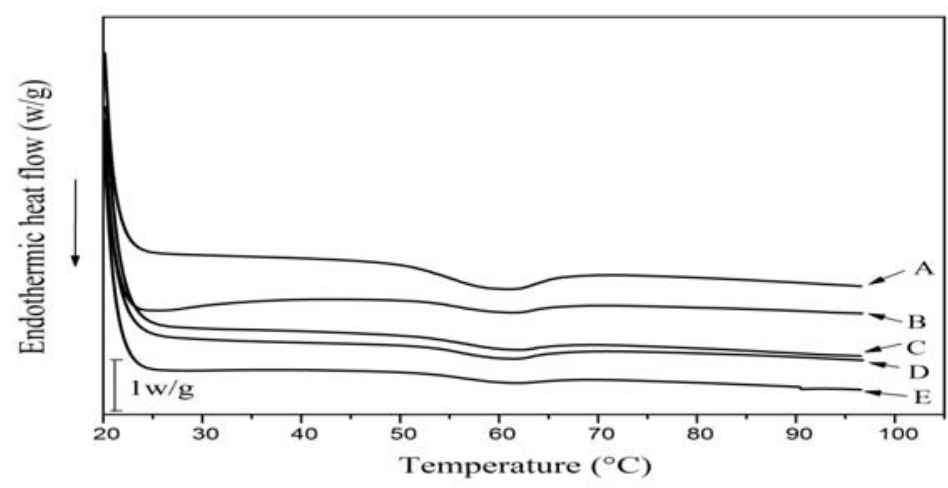

Fig.1 DSC thermograms of micronized tapioca starch

A, untreated $B$, micronized 15 min $C$, micronized 30 min D, micronized 45 min E, micronized $60 \mathrm{~min}$

Tips:Upward is exothermic,Downward is endothermic.

\subsection{Solubility and Swelling Properties}

\subsubsection{The Solubility of Tapioca Starch.}

The effect of different micronization time on the solubility of tapioca starch is shown in Fig.2.It was found that the solubility was obviously increased compared to control with micronization time increasing at the same temperature. The solubility of control was $0.93 \%$ at $50^{\circ} \mathrm{C}$, which was increased to $23.58 \%$ after treated for $15 \mathrm{~min}$, and the lowest values was observed after treated for $60 \mathrm{~min}$ $(81.63 \%)$.The reason may be that the mechanical force in the process of micronization destructed the lattice structure of starch,which contributed to the combination of the water molecule and the free hydroxyl of the starch.The starch can be precipitated from the particles at a lower temperature, resulting in a significant increase in the solubility of the micronizaed tapioca starch[8]. Similar result was also found by Fu et al. (2015) who reported that the solubility of indica rice starch was increased significantly from 1.34 to $32.4 \%[9]$.

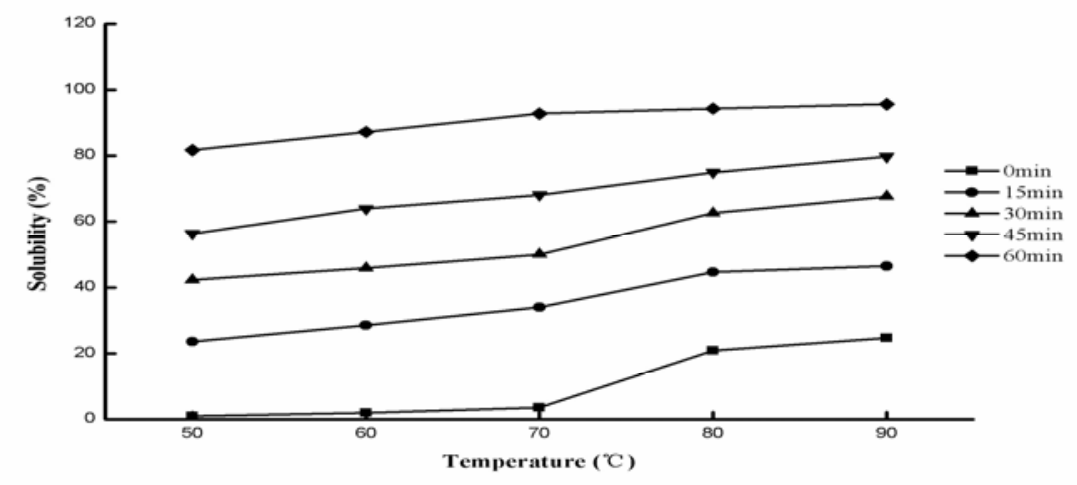

Fig.2 Solubility of tapioca starch at different temperatures in different micronization time

\subsubsection{The Swelling Properties of Tapioca Starch.}

The effect of different micronization time on the swelling properties of tapioca starch is shown in Fig.3.With the micronization time increasing,solubility had a sharp decrease at the same temperature. The reason could be that the crystal structure of starch granules is disintegrated and the degree of indentation is exacerbated by the continuous action of various mechanical forces. In addition, micronization can significantly increase the content of amylose and medium polymerization molecules in starch, Which play the role of thinner, resulting in a gradual decrease in dilation[10]. 


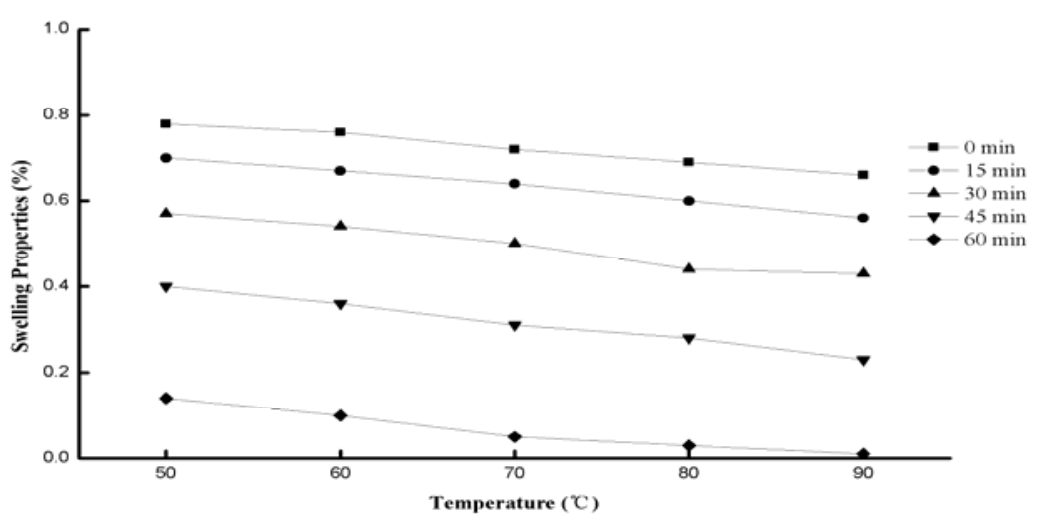

Fig.3 Swelling properties of tapioca starch at different temperatures in different micronization time

\subsection{Effect of Enzymolysis Properties.}

The effect of micronization time on the enzymolysis rate of tapioca starch is shown in Table 1. Enzymolysis rate of tapioca starch increased remarkably with increase of the micronization time. It is likely due to augmenting the contact area between the enzyme and the substrate because of the increasing of tapioca starch's solubility.Moreover, starch surface appear cracks and micropores after micronization,leading it easier for hydrolysis[11].The lamellar structure of starch granule was destroyed during the pulverization process, the double helix structure becomes loose[12], and the enzymolysis rate of the starch was increased.

Table 1 Enzymolysis rate of tapioca starch in different micronization time

\begin{tabular}{|lccccc|}
\hline Time $(\mathrm{min})$ & 0 & 15 & 30 & 45 & 60 \\
\hline $\begin{array}{l}\text { Enzymatic } \\
\text { hydrolysis } \\
\text { rate(g/min) }\end{array}$ & 0.0012 & 0.0258 & 0.0860 & 0.1024 & 0.1493 \\
\hline
\end{tabular}

\section{Conclusion}

The thermal properties analysis indicated that micronization makes the tapioca starch more easily to be gelatinized.Micronization effectively contributes to the solubility and enzymolysis rate of tapioca starch, whereas it decreases the swelling property obviously.Micronization is an practical technique to improve the quality of food, which play a huge role in the full utilization of food resources, the development of new functional foods and upgrade traditional crafts. The tapioca starch gains better solubility and faster enzymolysis rate to improve its pasting properties, which can increase its applicability in food industry.

\section{Acknowledgements}

The authors thank State Key Laboratory of Tropical Crop Products Processing of Ministry of Agriculture, Agricultural Products Processing Research Institute, Chinese Academy of Tropical Agricultural Sciences and for expert technical assistance. This study was financially supported by Hainan Natural Science Foundation (Project no. 20163113) ; National Natural Science Foundation of China (No. 31601397) and the Fundamental Scientific Research Funds for Chinese Academy of Tropical Agricultural Sciences (Project no.1630032015004).

\section{References}

[1]. Knight, J. W. Cassava Processing and Storage. International Development Research Centre (pp.76). Canada: IDRC, 1974. Rapaille, A., Vanhemelrijck, J. Modified starch. In A. Imeson 
(Ed.), Thickening and gellingagents for food (pp. 199-229). London: Blackie Academic and Professional,1997.

[2]. $\mathrm{Wu}, \mathrm{Q} ., \mathrm{Miao}, \mathrm{Y}$. Mechanochemical effects of micronization on enzymatic hydrolysis of corn flour [J]. Carbohydrate polymers, 2008, 72(3):398-402.

[3]. Fu, M. R., Chen, Q. M., Liu. F., et al. Effect of micronization on physicochemical properties and processing properties of glutinous rice [J]. Chinese Food and Nutrition, 2011, 17(6): 46-50.

[4]. Zhang, Y. J., Liu, W., Liu, C. M., et al. (2014). Retrogradation behaviour of high-amylose rice starch prepared by improved extrusion cooking technology[J]. Food Chemistry, 158, 255-261.

[5]. [6] Tang, H. B., Ma, J. B. Study on Synthesis Technology and Properties of Hydroxypropyl Potato Starch[J].Food Science,2005, 26(4): 167-170.

[6]. [7] Xie, R. H., Wang, S. X., Xie, X., et al. Application Status and Development Trend of Ultra-fine Grinding Technology[J].China Powder Technology, 2009(3): 64-67.

[7]. [8] Tu, Z. C., Ren, W., Liu, C. M., et al. Preparation and Properties of Nano-sized Rice Starch[J]. Journal of Agricultural Engineering, 2008, 24(1): 250-253.

[8]. [9] Fu, Z., Luo, S. J., BeMiller, J. N., et al. Influence of high-speed jet on solubility, rheological properties,morphology and crystalline structure of rice starch[J]. Starch-Stärke, 67(7-8), 595-603, 2015.

[9]. [10] Jin, S. Y., Chen, H. Z. Superfine grinding of steam-exploded rice straw and its enzymatic hydrolysis[J]. Biochemical Engineering Journal, 2006, 30: 225-230.

[10]. [11]Qi, G. D., Zhang, B. W., Zhang, G, X., et al. Study on the effect of Micronization Treatment on Processing Characteristics of Waxy Corn Starch[J]. Food Science and Technology, 2010, 35(3): 249-252.

[11]. [12] Kim G. W., Kim M. S., Sagara Y, et al. Determination of the viscoelastic properties of apple flesh under quasi-static compression based on finite element method optimization [J]. Food Sci. Technol. Res., 2008, 14(3): 221-231. 